\title{
Association between Pell and Gregory classification and the difficulty of the extraction of the lower third parties
}

\author{
Associação entre a classificação de Pell e Gregory \\ e a dificuldade da extração dos \\ terceiros molares inferiores
}

\author{
Erasmo Freitas de SOUZA JUNIOR ${ }^{1}$ iD https://orcid.org/0000-0003-1714-9226 \\ Janielma Azevedo SILVA ${ }^{1}$ iD https://orcid.org/0000-0002-5374-4324 \\ José lago Pereira de BRITO2 ID https://orcid.org/0000-0003-1802-8485 \\ Eudes Euler de Souza LUCENA1 iD https://orcid.org/0000-0003-3119-7822 \\ Hecio Henrique Araújo de MORAIS ${ }^{1}$ iD https://orcid.org/0000-0002-6450-1483
}

\section{ABSTRACT}

Lower third molar extraction is a common procedure in Oral and Maxillofacial Surgeons routine. However, even though this procedure is frequent, sometimes its course is unexpected. In this scenario, some developed classifications help to predict the difficulty level for such extractions. Objective: This study aimed to verify the association of Pell and Gregory classifications I and II and surgical difficulty through lower third molar extractions. Methods: Voluntary patients from the Dentistry Course of the State University of Rio Grande do Norte, between 16 and 45 years of age, who met the inclusion criteria, had their third molars classified according to Pell and Gregory. Results: A total of 42 elements were extracted. There were no statistically significant differences for the correlation of Pell and Gregory classification with the surgical difficulty considering the variables such as surgery time $(p=0.419)$, osteotomy needs ( $p=0.428)$ and number of anesthetic tubes (0.939). As for the need for odontosection, only when comparing the teeth classified as Al and IIA, the difference in favor of Al elements was statistically significant $(p=0.008)$. There were no accidents or complications. Conclusion: Pell and Gregory classification was not a good predictor of surgical difficulty, and further studies on this subject are recommended.

Indexing terms: Molar, third. Tooth extraction. Mandible.

\section{RESUMO}

A exodontia dos terceiros molares inferiores é um procedimento comum na rotina dos Cirurgiões Bucomaxilofaciais. Entretanto, mesmo este procedimento sendo frequente, por vezes, o seu curso se mostra de forma inesperada. Neste cenário, algumas classificações

\footnotetext{
$\boldsymbol{\nabla v} \mathbf{v}$

1 Universidade do Estado do Rio Grande do Norte, Faculdade de Ciências da Saúde, Programa de Pós-Graduação em Saúde e Sociedade. Rua Miguel Antônio da Silva Neto, s/n, Aeroporto, 59607-360, Mossoró, RN, Brasil. Correspondence to: EF SOUZA JUNIOR. E-mail: <erasmo_jn@hotmail.com>.

2 Universidade do Estado do Rio Grande do Norte, Faculdade de Ciências da Saúde, Curso de Odontologia. Caicó, RN, Brasil.

$\boldsymbol{\nabla} \boldsymbol{\nabla} \boldsymbol{v}$

How to cite this article

Souza Junior EF, SILVA JA, Brito JIP, Lucena EES, Morais HHA. Association between Pell and Gregory classification and the difficulty of the extraction of the lower third parties. RGO, Rev Gaúch Odontol. 2021;69:e20210021. http://dx.doi.org/10.1590/1981-86372021002120190101
} 
desenvolvidas auxiliam na predição do nível de dificuldade para tais extrações. Objetivo: Este trabalho objetivou, por meio de extrações de terceiros molares inferiores, verificar a associação das classificações I e /l de Pell e Gregory e a dificuldade cirúrgica. Métodos: Pacientes voluntários do Curso de Odontologia da Universidade do Estado do Rio Grande do Norte, entre a faixa etária de 16 a 45 anos, que se encaixaram nos critérios de inclusão, tiveram seus terceiros molares classificados de acordo com Pell e Gregory e extraídos. Resultados: Um total de 42 elementos foram extraídos. Não existiram diferenças estatisticamente significantes para a correlação da classificação de Pell e Gregory com a dificuldade cirúrgica levando-se em conta as variáveis tempo de cirurgia ( $p=$ $0,419)$, necessidades de osteotomia $(p=0,428)$ e quantidade de anestubes $(0,939)$, quanto a necessidade de odontossecção, apenas quando comparados os dentes classificados como IA e IIA, a diferença a favor dos elementos IA foi estatisticamente significativa ( $p=$ 0,008), inexistindo acidentes e complicações. Conclusão: A classificação de Pell e Gregory não se mostrou como um bom preditor da dificuldade cirúrgica, sendo recomendado que novos estudos sejam realizados sobre essa temática.

Termos de indexação: Dente serotino. Extração dentária. Mandibula.

\section{INTRODUCTION}

Third molars are the dental elements most susceptible to embedding and impaction, since they are the last to form and often face the lack of space for their complete eruption, in addition to the interference of the second molar and a higher density in the bone structure and overlying soft tissue. This situation is more common in the mandible than in the maxilla and its exodontia is among the most common procedures in the Oral and Maxillofacial surgeon routine [1-10].

The ordinary surgical removal of these elements occurs because they are recurrently associated with morbidities, such as root resorption of the second molar, perocoronaritis, cysts, neoplasias, mandibular fractures, facilitation of orthodontic treatment, cavities and odontogenic abscesses $[1,2,4,6,11]$.

However, this procedure tends to involve the traumatic manipulation of bone, connective and muscular tissues, which inclines the formation of edema, pain, trismus, infection and nerve injury, and which may occur isolated or combined in the post-surgery $[7,9,10]$.

Therefore, an adequate clinical and radiographic evaluation in the pre-surgical period is of crucial importance in order to observe the characteristics that may hinder the surgical procedure, such as age, body mass index (BMI), ethnicity, surgeon experience, tooth, impaction, development, root curvature and width, relation with mandibular canal, and patient anxiety. In view of this, the risk of accidents and complications can be reduced, either through the correct indication of the appropriate surgical environment (outpatient or hospital), or even with the referral to a more experienced professional, in addition to informing the patient on the potential risks of the surgery that he/she is about to undergo (indispensable prerogative in view of an event of subsequent litigation) $[6,8,12-14]$.
Regarding the tooth impaction, considered by many as an important predictor of the surgery complexity, Pell and Gregory classification labels the tooth according to its relation with the mandibular ramus (class I: out of mandibular ramus; class II: partially inserted in the anterior portion of the mandibular ramus, and class III: fully inserted in the mandibular ramus), and with the occlusal plane (class A: same level of the second molar occlusal plane; class $\mathrm{B}$ : between the occlusal plane and the second molar cervical line, and class C: below the second molar cervical line). This classification is not only widely mentioned in oral and maxillofacial surgery papers, but it is also widely used as a means of communication among dental surgeons, through its predominant workability in the didactics of undergraduate courses $[4-6,8,10,13]$.

Therefore, this study aimed to investigate the association of lower third molars extractions labeled according to Pell and Gregory, comparing the class I and II classifications of third molars, regarding the time required for their removal, and also the needs of osteotomy, odontosection, number of anesthetic tubes, and the existence of accidents and complications, also observing the variables such as age, weight and height of the patients.

\section{METHODS}

The data of this study were obtained after the submission and approval of the research project by the Research Ethics Committee of the State University of Rio Grande do Norte (UERN) under the opinion No. 2.087.249, and it is also compliant with the Declaration of Helsinki and with the Guidelines of the National Health Council (CNS - Resolution 466/12, Brazil).

As inclusion criteria, there were volunteer patients, from spontaneous demand, cared in the premises of the 
Dentistry Course of UERN, in the age group between 16 and 45 years, who agreed to participate in the research after reading the Free and Informed Consent Form (TCLE), classified according to the American Society of Anesthesiology (ASA) [15], as group I (normal healthy, with no systemic alterations and no continuous use of medicines), with the indication of exodontia of lower third molars. Those who did not meet the planning of surgical and anesthetic techniques were excluded. And the sampling occurred for convenience, through the spontaneous search of patients at the Oral and Maxillofacial Surgery service of the Dentistry Course of UERN, during the data collection phase of this research.

Regarding the surgical procedure itself, the surgeon was the same for all cases, which was a Dental surgeon specialist in Oral and Maxillofacial Surgery and Traumatology, and only healthy patients were a target for this research, not using antibiotics in the period prior to the surgery, as indicated by the American Association of Cardiology. Patients only performed the mouthwash with chlorhexidine at $0.12 \%$ for one minute, and using sterile gauze. They received topical friction, extra oral, of chlorhexidine $2 \%$ (before surgery), in order to provide a local bacterial reduction [16].

Next, the patients underwent local anesthesia with anticaine $4 \%$ associated with epinephrine 1:100,000 by regional blocking of lower, lingual and oral alveolar nerves, with the direct technique in a surgical environment, with a strict control of the aseptic chain. The routine procedures for the exodontia of the lower third molars were followed and, with the surgical field prepared, an incision was performed for the cases that so required (with scalpel handle number 3 and blade number 15) in the distal region and in the gingival crevice, through vestibule, of the second molar and, also for the required cases, a lateral oblique incision by mesial and vestibule of this tooth was made, returning a muco-periosteal flap. And some cases required additional procedures, such as osteotomies and/or odontosections, with rotational instruments and under manual irrigation with $0.9 \%$ saline, followed by the avulsion of the third molar, cleaning the surgical wound through irrigation with $0.9 \%$ saline, repositioning of the flap and suturing. Sutures were removed after a week of after-surgery.

Anti-inflammatory and analgesic were prescribed for minimizing the pain and edema, collutory for cleaning the surgical site and controlling halitosis, and antibiotic as a way to prevent possible infectious processes.
Regarding the studied variables, demographic characteristics (gender, age, ethnicity, weight, height, and inclusion classification) were recorded. Also, surgical time (from soft tissue incision to the end of the suture procedure), number of anesthetic tubes administered, need for osteotomy and odontosection, accidents and complications were described.

A database was generated and analyzed using the SPSS statistical package version 20, with subsequent verification of typing consistency. After the final structuring of the database, a descriptive analysis of all data related to demographic variables was initially performed: age, weight, gender, ethnicity, height and degree of embedding.

For all tests, the significance level of $5 \%$ was adopted. The means between the groups for the variables such as surgery time, number of anesthetic tubes used and need for osteotomy were compared through the Kruskal-Wallis test. And the variable need for odontosection was compared by the Independence Chisquare test with Yates continuity correction, considering statistically significant " $p$ " values lower than 0.05 .

\section{RESULTS}

\section{Patient characteristics}

Patient recruitment occurred from June 20, 2017 to March 29, 2019. A total of 22 patients were included in the inclusion criteria, and, at the end of data collection, twenty individuals had undergone the removal of the two lower third molars, while two individuals underwent to only one surgical procedure each, totaling a sample of 42 extracted elements. This consisted of $95.2 \%$ of female and $4.8 \%$ male patients, with ages ranging from 17 to 39 years, with a mean of $23.98 \pm 5.06$ years. Patients had weight from $51 \mathrm{~kg}$ to $78 \mathrm{~kg}$, with a mean of $60.23 \pm 6.84$ $\mathrm{kg}$ and height between $1.46 \mathrm{~m}$ and $1.70 \mathrm{~m}$ with a mean of $1.58 \pm 0.05 \mathrm{~m}$. Regarding ethnicity/color $52.4 \%$ declared themselves white and $47.6 \%$ as brown. Regarding Pell and Gregory classification, the following degrees of third molars embedding were found: IA 17 (40.5\%); IB 3 (7.1\%); IIA 12 (28.6\%); IIB 6 (14.3\%); IIC 4 (9.5\%).

The summary of patients' characteristics can be found in Table 1. 
Table 1. Arithmetic means and standard deviations (age, weight and height) and percentages (gender, ethnicity/color and embedding degrees) of patients.

\begin{tabular}{|c|c|c|c|c|}
\hline \multicolumn{5}{|c|}{ Patient characteristics } \\
\hline \multicolumn{5}{|c|}{ Patients gender } \\
\hline & Male & & \multicolumn{2}{|c|}{ Percentage } \\
\hline & Female & & & $95.2 \%$ \\
\hline & Total & & & $95.2 \%$ \\
\hline \multicolumn{5}{|c|}{ Age in years } \\
\hline Age in years & 17 & 39 & 23,98 & $\pm 5,06$ \\
\hline \multicolumn{5}{|c|}{ Weight } \\
\hline \multirow{2}{*}{ Weight in kilograms } & Minimum & Maximum & Mean & Standard Deviation \\
\hline & 51 & 78 & 60.23 & \pm 6.84 \\
\hline \multicolumn{5}{|c|}{ Height in meters } \\
\hline \multicolumn{5}{|c|}{ Percentage } \\
\hline & White & & \multicolumn{2}{|c|}{$52.4 \%$} \\
\hline & Brown & & \multicolumn{2}{|c|}{$47.6 \%$} \\
\hline & Total & & \multicolumn{2}{|c|}{$100 \%$} \\
\hline \multicolumn{5}{|c|}{ Embedding degrees of Pell and Gregory } \\
\hline & \multicolumn{2}{|c|}{ Frequency } & \multicolumn{2}{|c|}{ Percentage } \\
\hline $\mathrm{IA}$ & \multicolumn{2}{|c|}{17} & \multicolumn{2}{|c|}{$40.5 \%$} \\
\hline $\mathrm{IB}$ & \multicolumn{2}{|c|}{3} & \multicolumn{2}{|c|}{$7.1 \%$} \\
\hline$\| \mathrm{A}$ & \multicolumn{2}{|c|}{12} & \multicolumn{2}{|c|}{$28.6 \%$} \\
\hline
\end{tabular}

\section{Surgeries characteristics}

The surgeries had, according to each Pell and Gregory classification, the following time means by decreasing order: IIB: $33.67 \pm 3.38 \mathrm{~min}$; IIA: $33.00 \pm 19.89 \mathrm{~min}$; IA: $30.71 \pm 18.45 \mathrm{~min}$; IIC: $30.50 \pm 0.57 \mathrm{~min}$ and IB: $18.67 \pm$ $0.57 \mathrm{~min}$. And regarding the mean amount of anesthetic tubes used in the surgical procedures for each group, the results obtained in decreasing order were the following: IIC
$2.25 \pm 0.86 ; \|$ A: $2.00 \pm 0.60 ;$ IA: $1.94 \pm 0.52 ;$ IIB: $1.83 \pm$ 0.68 and IB: $1.76 \pm 0.40$. Kruskal-Wallis test showed a p-value greater than 0.05 , both in the comparison between surgical times and between the number of anesthetic tubes used for each group, so the differences found were not statistically significant.

Summaries of the values found in the variables such as surgery time and used anesthetic tubes can be observed in Tables 2 and 3.

Table 2. Arithmetic means, standard deviations and p-value by Kruskal-Wallis test of the surgery time variable.

\begin{tabular}{lccc}
\hline \multicolumn{3}{c}{ Surgery time } \\
\hline Groups & Mean & Standard deviation & p-value \\
\hline IA & 30.71 & 18.45 & 0.57 \\
IB & 18.67 & 19.89 & 0.419 \\
IIA & 33.00 & 3.38 & 0.57 \\
IIB & 33.67 & 30.50 & IC \\
\hline
\end{tabular}


Table 3. Arithmetic means, standard deviations and p-value by Kruskal-Wallis test of the amount of used anesthetic tubes variable.

\begin{tabular}{lccc}
\hline & \multicolumn{2}{c}{ Quantity of used Anesthetic tubes } \\
\hline Groups & Mean & Standard deviation & p-value \\
\hline IA & 1.94 & 0.52 \\
IB & 1.76 & 0.40 & 0.939 \\
IIA & 2.00 & 0.60 & 0.68 \\
IIB & 1.83 & 0.86 & \\
IIC & 2.25 & . & \\
\hline
\end{tabular}

Regarding the need for osteotomy, the mean amount of bone faces removed for the extraction of each third molar was calculated, obtaining the following values in decreasing order: $\mathrm{IB}: 2.00 \pm 0.00 ; \mathrm{IIC}: 2.00 \pm 0.00 ; \mathrm{IB}$ : $1.67 \pm 0.57 ; \mathrm{IA:} 1.65 \pm 0.78$ and $I \mathrm{AA}: 1.50 \pm 0.79$. KruskalWallis test showed a p-value greater than 0.05 in the comparisons between groups, so the differences found were not statistically significant.

The summary of the values found in the variable concerning the number of faces that required osteotomy can be found in Table 4.

For the variable need for odontosection, all groups were compared to each other in order to observe the differences between those who required or not this surgical step, for that, an Independence Chi-square test was performed with correction of Yates continuity. A statistically significant difference can be observed, where p-value was less than 0.05 , in the comparison between teeth surgeries with embedding Al vs. those with embedding IIA, according to Pell and Gregory classification, for all other comparisons the $p$-value was greater than 0.05 , and these were not statistically significant.

The summary of the values found in the variable regarding the need for odontosection can be found in table 5 .
During the course of the collection phase, there was no occurrence of accidents or complications for any of the 42 surgeries.

\section{DISCUSSION}

The prediction of the difficulty level of any dental procedure is of paramount importance for its conduction in the best possible way. Regarding the exodontia procedure of the lower third molars, some classifications try to indicate the complexity level based on some clinical and radiographic parameters, besides facilitating the interprofessional communication. Among these parameters, surgical time, number of anesthetic tubes to be used, and the need for osteotomy and odontosection, are particularly relevant in the observance of this prediction.

In this context, in several studies in the Oral and Maxillofacial surgery area, the use of the Pell and Gregory classification is a routine, both in isolation or in combination with other classifications, and also in epidemiological studies and those studies aimed at its use as a predictive factor for the surgery difficulty of the third molars. This is because it is a very didactic classification $[2,8]$.

Analyzing the results of this study with other studies, we can obtain some observations that deserve to

Table 4. Arithmetic means, standard deviations and p-value by Kruskal-Wallis test of the amount of faces requiring osteotomy.

\begin{tabular}{lccc}
\hline \multicolumn{3}{c}{ Need for osteotomy } \\
\hline Groups & Mean & Standard deviation & $p$-value \\
\hline IA & 1.65 & 0.78 & 0.57 \\
IB & 1.67 & 0.79 & 0.428 \\
IIA & 1.50 & 0.00 & \\
IIB & 2.00 & 0.00 & \\
IIC & 2.00 & . & \\
\hline
\end{tabular}


Table 5. Frequency and p-value by the Independence Chi-square test with Yates continuity correction of the need for odontosection.

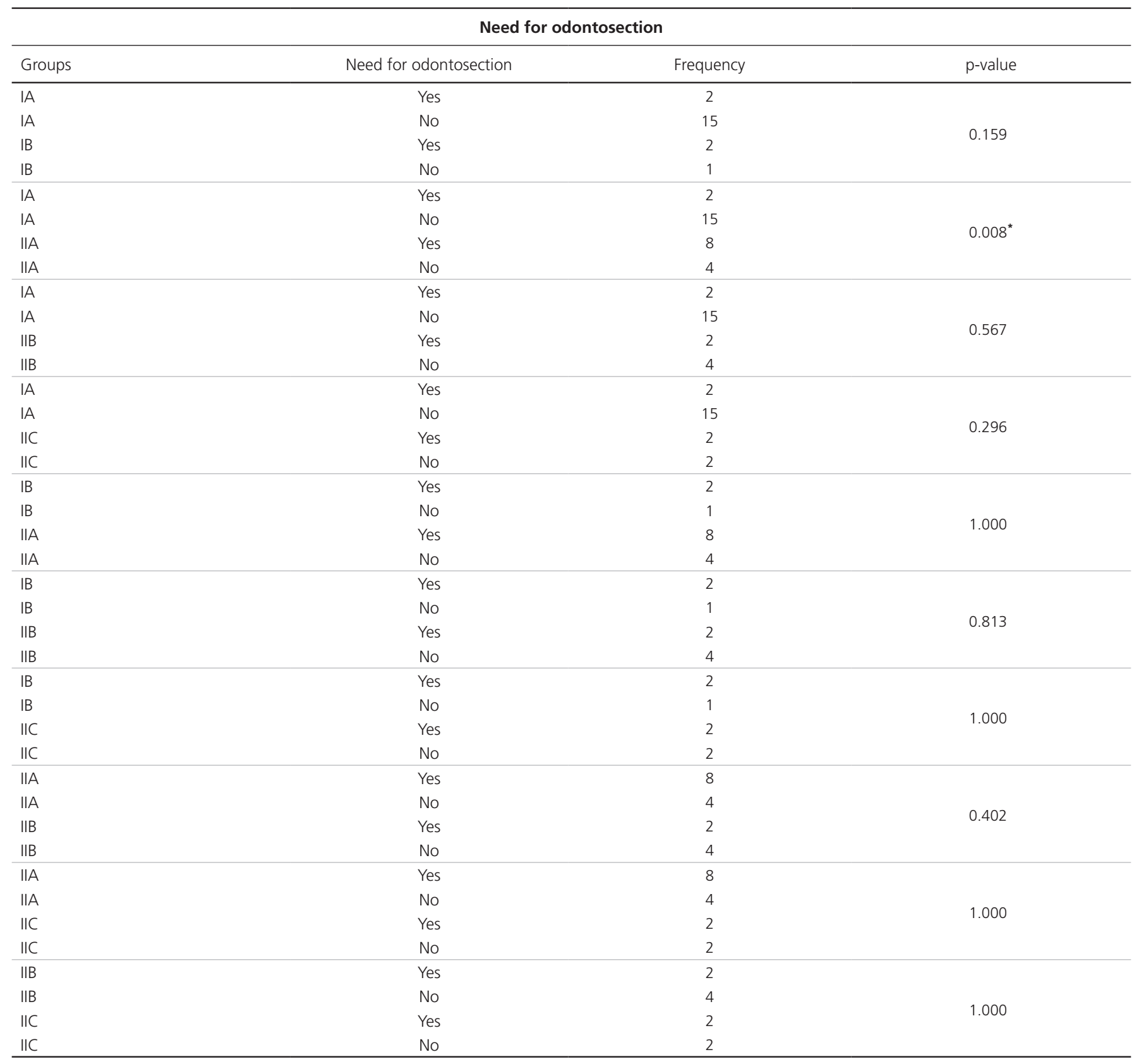

Note: "p-value was less than 0.05

be highlighted, because this can help the Dental surgeon in the perception of certain situations that occur in the daily clinic.

Regarding the age of the patients, it was noticed that the individuals had a mean age that could be pointed out as that of young adults $(23.98 \pm 5.06$ years), which is something positive, because bone corticals become less elastic in older individuals due to a reduction of its organic component [3]. These means are compatible with those of other studies that also focused on the extraction of third molars, such as those of Carvalho \& Vasconcelos [17] (21.8 \pm 2.4 years); Park [8] (most of them between 20 and 29 years); Pippi [13] (27.36 \pm 11.21 years); Al-Samman [14] (27.5 \pm 5.7 years); Stacchi et al. [2] (men: $30.5 \pm 10.7$ years; women: $27.5 \pm 11.3$ years); Altan \& Akbulut [4] (26.42 \pm 7,.6); Marqués et al. [11] (27.32 years) and González et al. [9] (23.58 \pm 3.34 years). This frequency of age can be explained by the fact that studies, basically, use volunteers 
who spontaneously seek the service in institutions where researchers are linked to and tendentiously this demand occurs or by orthodontic indication (common treatment at this stage of life) or by the occurrence of a painful and/ or infectious process, which is common in the eruption period of this element in the dental arch, which tends to occur between the end of the second decade of life and the beginning of the third one.

Concerning the Pell and Gregory classification, the results of this study pointed out that the relations with the occlusal plane A and B occurred more frequently, another relevant point to be mentioned was the fact that during the data collection phase there was no demand for patient who had any class III element, and such data agrees with the following studies: Carvalho \& Vasconcelos [17]; Park [8]; Pippi [13]; Marqués et al. [11] and Primo et al. [6].

Regarding the surgery duration, patient satisfaction is increased when the procedure occurs within the expected time, which is an important factor for planning clinical and organizational aspects of the extraction $[2,13]$. In this study, the mean time of surgery occurred from $18.67 \pm 0.57 \mathrm{~min}$ (lowest mean among groups, occurring for those in class IB) to $33.67 \pm 3.38$ min (highest mean among groups, occurring for those in class IIB), and the difference in this variable is not, in each studied group, statistically significant to correlate them with difficulty $(p=0.419)$. Comparing with other studies, the surgical time means were relatively higher than that in the study by Komerik et al. [3] (12.5 $\pm 10.5 \mathrm{~min})$, but close to those found by Pippi [13] (30.65 \pm 1.97min), González et al. [9] (19.02 \pm 5.38min), Carvalho \& Vasconcelos [17] (22 \pm 3.5 min), Stacchi et al. [2] (24.1 $\pm 22.2 \mathrm{~min})$.

The means of used anesthetic tubes was low, especially when compared to the maximum recommended dose, taking into account both the average weight in kilograms and the minimum weight value recorded, and articaine $4 \%$ associated with epinephrine 1:100,000 was shown as an excellent anesthetic, which matches with the statement that this substance has a high lipid solubility, allowing its diffusion more easily when compared to other local anesthetics [18]. The differences in the variable amount of used anesthetic tubes were not statistically significant in each studied group to correlate them with difficulty $(p=0.939)$.

Regarding other surgical procedures, Carvalho \& Vasconcelos [17] point out osteotomy as the most used surgical technique for the removal of the lower third molars in their research $(57.9 \%)$ and the tooth position ( $p=0.001$ ) was one of the factors with a statistically significant difference for the surgery difficulty, but apparently not influencing the occurrence of complications.

And Park [8] in a retrospective study involving 680 patients and 762 impacted mandibular third molars, the extraction difficulty level was investigated based on the subjective degree of the surgeon on a five-point difficulty scale, and the cases were classified into three groups: "not difficult" (1-3), "moderately difficult" (4) and "very difficult" (5). As a result, 542 extractions were considered not difficult $(71.1 \%), 124$ were moderately difficult $(16.3 \%)$ and 96 were very difficult (12.6\%), and in 103 cases the dental position was related to presumed difficult extractions. And according to Pell-Gregory classification, the probability order of difficult extractions was C2, B2 and B3. This study considered the two factors (depth of impaction and the relation with the mandibular ramus) separately, observing that the impaction depth was statistically associated with the extraction difficulty, while the relation with the mandibular ramus had no association.

It is important to reiterate that Pell and Gregory classification can be used in isolation or in combination with other classifications, and its association with that of Winter, which defines the element according to axis angulation as mesioangular, vertical, horizontal and detoangular impactions, can transmit more information about anatomical obstacles to perform surgeries [8]. However, in Park's study [8], both Winter classification evaluated individually, and its combination with Pell and Gregory classification, through the Pederson index, showed no statistically significant difference in surgical difficulty. In this research, Pell and Gregory classification was used independently of other classifications, such that of Winter.

Komerik et al. [3] aiming to compare the predictive capacity of experienced oral and maxillofacial surgeons with that of residents regarding the removal difficulty of the third molar, study conducted a study including a total of 200 patients. For both groups, the difficulty level was correctly estimated in just over half of the cases. Among the reasons for the mentioned difficulties, the repetition of anesthesia was reported on 3 occasions. In the study, a total of 79 extraction cases was by incision of soft tissues (mean duration of 6.25 minutes) and in 41 it was necessary to section the bone, crown and root of the tooth (mean duration of 26 minutes). In conclusion, the pre-surgery estimate of surgical difficulty of the third mandibular molar 
removal was not reliable, not only for residents, but also for senior surgeons.

In view of the remarks of the last three mentioned studies, it is important to point out that in this study, the osteotomy was a resource often used, with no statistically significant difference that could associate the tooth position and osteotomy with the surgical difficulty. And regarding the need for odontosection, when comparing teeth classified as Al and AIA, the difference in favor of Al elements was statistically significant $(p=0.008)$, which presented less need for this surgical step.

Regarding complications, which are defined as any unexpected event in a surgical situation that requires additional management beyond the originally planned, the damage caused by a complication can lead to considered morbidities, with loss of days of labor activity, several postsurgery sessions, and also possible legal actions [17].

In this context, Genú \& Vasconcelos [19] present a study with the objective of verifying the relationship between the use of dental cutting and the possibility of damage to the Lower Alveolar Nerve (LAN). The results of needlestick and directional brush tests recorded four (8\%) cases of LAN injury, and two were classified as hypoesthesia and two as paresthesia. All four were in class II of Pell and Gregory classification, two in position B and two in position $C$, but no statistical association was found.

On the other hand, Marques et al. [11] pointed out that the third vertical molars in positions IIA and IIB of Pell and Gregory classification, with partial mucosa and bone coverage, were the most susceptible to undesirable outcomes, with the highest number of infectious, noninfectious and neurological complications. In this study there was no record of complications.

\section{CONCLUSION}

The surgical time estimate is an important factor for planning clinical and organizational aspects of the impacted lower third molar extraction. And an appropriate classification system can help the clinician in the diagnosis of the extractions real difficulty. In this study, Pell and Gregory classification, although it is easy to understand in the interprofessional communication, was not shown as a good predictor of surgical difficulty, especially when not associated with other classification systems, and it is recommended that further studies are conducted on this topic.
Collaborators

EF SOUZA JUNIOR, data collection, analysis and interpretation, writing and relevant critical review of the intellectual content of the manuscript, final approval of the version to be published and responsibility for all aspects of the research, also ensuring its accuracy and integrity. HHA MORAIS and JIP BRITO, data collection, final approval of the version to be published and responsible for all aspects of the study, also ensuring its accuracy and integrity. JA SILVA, writing and relevant critical review of the intellectual content of the manuscript, final approval of the version to be published and responsibility for all aspects of the study, also ensuring its accuracy and integrity. EES LUCENA, analysis and interpretation of data, final approval of the version to be published and responsibility for all aspects of the work, also ensuring its accuracy and integrity.

\section{REFERENCES}

1. Melek Tassoker, Hatice Kok, Sevgi Sener. Is there a possible association between the skeletal face types and third molar impaction? a retrospective radiographic study. Pr Princ do Med. 2019; 28(1):70-74. http://dx.doi.org/10.1159/000495005

2. Stacchi C, Daugela P, Berton F, Lombardi T, Andriulionis T, Perinetti DDSG, et al. Oral surgery A classification for assessing surgical difficulty in the extraction of mandibular impacted third molars : Description and clinical validation. Quintessence Int. 2018;49(9):745-753. http://dx.doi.org/10.3290/j.qi.a40778

3. Komerik N, Muglali M, Tas B. Difficulty of impacted mandibular third molar tooth removal : predictive ability of senior surgeons and residents. J Oral Maxillofac Surg. 2014;72 (6):1062.e1-6. http://dx.doi.org/10.1016/ j.joms.2014.01.023

4. Altan A, Akbulut N. Does the angulation of an impacted mandibular third molar affect the prevalence of preoperative pathoses? J Dent (Shiraz). 2019;20(1):48-52

5. Al-dajani M, Abouonq AO, Almohammadi TA, Alruwaili MK, Alswilem RO, Alzoubi IA. A cohort study of the patterns of third molar impaction in panoramic radiographs in saudi population. Open Dent J. 2017;11:648-660. http://dx.doi. org/10.2174 / 1874210601711010648

6. Primo BT, Angelo M, Scheffer R, Rivaldo EG. Evaluation of 1211 Third molars positions according to the classification of Winter , Pell \& Gregory. Int J Odontostomat. 2017;11(1):61-5.

7. Ryalat S, Alryalat SA, Kassob Z, Hassona Y, Al-shayyab MH. Impaction of lower third molars and their association with age : radiological perspectives. BMC Oral Health. 2018;18(1): 58. http://dx.doi.org/10.1186 / s12903-018-0519-1

8. Park K, Park K. Which factors are associated with difficult surgical extraction of impacted lower third molars? J Coreano Assoc Oral Maxillofac Surg . 2016;42(5):251-258. http:// dx.doi.org/10.5125 / jkaoms.2016.42.5.251

9. Manuel P, Esparza-villalpando V, Mart R, Pozos-guill A. Clinical and radiographic characteristics as predictive factors of 
swelling and trismus after mandibular third molar surgery : a longitudinal approach. Dor Res Manag. 2018;2018:7938492. http://dx.doi.org/10.1155 / 2018/7938492

10. Freudlsperger $C$, Deiss T. Influence of lower third molar anatomic position on postoperative. J Oral Maxillofac

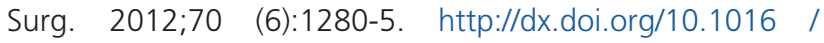
j.joms.2011.12.014

11. Almendros-marqués N, Berini-aytés L. Influence of lower third molar position on the incidence of preoperative complications. Oral Surg Oral Med Oral Pathol Oral Radiol Endod. 2006;102(6):725-32. http://dx.doi.org/10.1016 / j.tripleo.2006.01.006

12. Carvalho RWF, Vasconcelos BC. Pernambuco index: predictability of the complexity of surgery for impacted lower third molars. Int J Oral Maxillofac Surg. 2018;47(2):234-240. http://dx.doi.org/10.1016 / j.ijom.2017.07.013

13. Pippi R, Pippi R. Evaluation capability of surgical difficulty in the extraction of impacted mandibular third molars: a retrospective study from a post-graduate institution. Ann Stomatol (Roma). 2014;5(1):7-14.

14. Al-samman AA. Evaluation of Kharma scale as a predictor of lower third molar extraction difficulty. Med Oral Patol Oral Cir Bucal . 2017;22(6):e796-e799. http://dx.doi.org/10.4317 / medoral.22082
15. AAOMS. Parameters and pathways: clinical practice guidelines for oral and maxillofacial surgery. Version 3.0. Rosemont (IL): American Association of Oral and Maxillofacial Surgeons; 2012.

16. Rodríguez SF, Rodríguez AC, Arteagoitia Cl. Does Chlorhexidine prevent alveolar osteitis after third molar extractions? systematic review and meta-analysis. J Oral Maxillofac Surg. 2017;75(5):901914. http://dx.doi.org/10.1016/j.joms.2017.01.002

17. Carvalho RWF. Assessment of factors associated with surgical difficulty during removal of impacted lower third molars. J Oral Maxillofac Surg. 2011;69(11):2714-21. http://dx.doi. org/10.1016 / j.joms.2011.02.097

18. Kim C,HwangKG, ParkCJ.Anestesialocal paraextraçãodeterceiros molares inferiores. J Anesth Dent Pain Med. 2018;18(5):287. http://dx.doi.org/10.17245/ jdapm.2018.18.5.287

19. Paper C, Surgery O. Influence of the tooth section technique in alveolar nerve damage after surgery of impacted lower third molars. Int J Oral Maxillofac Surg. 2008;37(10):923-8. http://dx.doi.org/10.1016/ j.ijom.2008.05.016

Received on: 18/6/2019

Final version resubmitted on: 8/12/2019

Approved on: 18/2/2020 